\title{
Effect of silibinin on the expression of MMP2, MMP3, MMP9 and TIMP2 in kidney and lung after hepatic ischemia/reperfusion injury in an experimental rat model
}

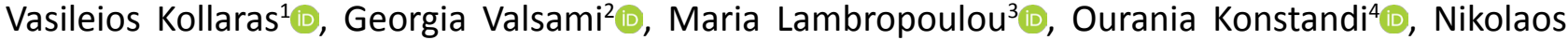 \\ Kostomistsopoulos ${ }^{5}$, Emmanouil Pikoulis ${ }^{6}$, Constantinos Simopoulos ${ }^{7}$, Alexandra Tsaroucha ${ }^{8^{*}}$ (D)
}

\footnotetext{
1. MSc. Postgraduate Program in Hepatobiliary/Pancreatic Surgery - Faculty of Medicine - Democritus University of Thrace - Dragana, Greece.

2. PhD. School of Health Sciences - Department of Pharmacy - National and Kapodistrian University of Athens, Greece.

3. PhD. Laboratory of Histology-Embryology - Faculty of Medicine - Democritus University of Thrace - Dragana, Greece.

4. PhD. Faculty of Cell Biology and Biophysics - Department of Biology - School of Science - National and Kapodistrian University of Athens, Greece.

5. DVM, PhD. Department of Experimental Surgery - Bioresearch Foundation of the Academy of Athens - Athens, Greece.

6. PhD. 3rd Department of Surgery - School of Medicine - National and Kapodistrian University of Athens - Attikon Hospital, Greece.

7. PhD. 2nd Department of Surgery - Faculty of Medicine - Democritus University of Thrace - Alexandroupolis, Greece.

8. PhD. Laboratory of Experimental Surgery and Surgical Research - Faculty of Medicine - Democritus University of Thrace - Dragana, Greece.
}

\begin{abstract}
Purpose: The protective effect of silibinin on kidney and lung parenchyma during hepatic ischemia/ reperfusion injury (IRI) is explored. Methods: Sixty-three Wistar rats were separated into three groups: sham; control (45 min IRI); and silibinin ( $200 \mu \mathrm{L}$ silibinin administration after $45 \mathrm{~min}$ of ischemia and before reperfusion). Immunohistochemistry and real-time quantitative reverse transcription polymerase chain reaction (qRT-PCR) were used to evaluate the expression levels of MMP2, MMP3, MMP9, and TIMP2 on kidney and lung. Results: Comparing sham vs. control groups, confirmed that hepatic IRI increased both renal and lung MMP2, MMP3, MMP9 and TIMP2 expressions starting at $180 \mathrm{~min}(\mathrm{p}<0.001)$. Comparison of the control vs. silibinin groups showed a statistically significant decrease in the expression levels of MMP2, MMP3, and MMP9 and increase of TIMP2 in kidney and lung parenchyma. The starting point of this decrease was at $120 \mathrm{~min}$ after reperfusion, both for kidney and lung parameters, and it was statistically significant at $240 \mathrm{~min}(\mathrm{p}<0.001)$ for kidney, while silibinin showed a peak of lung protection at $180 \mathrm{~min}$ after hepatic reperfusion $(p<0.001)$. Conclusion: Hepatic IRI causes distant kidney and lung damage, while a statistically significant protective action, both on kidney and lung parenchyma, is conveyed by the intravenous administration of silibinin.
\end{abstract}

Key words: Silybin. Reperfusion Injury. Immunohistochemistry. Liver. Rats.

*Corresponding author: atsarouc@med.duth.gr | 30-694 4468515

Received: May 13, 2021 | Review: July 10, 2021 | Accepted: Aug 12, 2021

Conflict of interest: Nothing to declare.

Research performed at Laboratory of Experimental Surgery and Surgical Research, Faculty of Medicine, Democritus University of Thrace, Dragana, Greece. 


\section{Introduction}

In liver surgery, clinical situations exist in which periods of ischemia are required, such as during trauma, removal of liver tumors, vascular reconstruction, and transplantation ${ }^{1-3}$. One of the most common, time honored, blood inflow control manipulations is the Pringle maneuver, which is performed by clamping the hepatic pedicle, thereby occluding both portal vein and hepatic artery $\mathrm{y}^{4}$. This process results in severe liver injury and disfunction ${ }^{5-9}$, making ischemia reperfusion injury a major cause of morbidity and mortality in liver resection and liver transplantation surgery ${ }^{10,11}$. Ischemia reperfusion injury, aside from the hepatic damage, also affects other remote organs such as the kidneys, the lungs, the myocardium, the adrenal glands, and the small intestine ${ }^{12}$.

The etiology of acute kidney injury (AKI) is thought to be multifactorial and is usually attributed to renal ischemia due to hemodynamic instability in the perioperative period $^{13}$. In rodents, hepatic ischemia/reperfusion injury (IRI) has been shown to cause AKI ${ }^{14,15}$, although it is not clear at what stage of the IRI process AKI occurs. There is emerging evidence that suggests multiple molecular mechanisms in the pathophysiology of AKI associated with liver IRI. The first step seems to be portal hypertension due to portal pedicle occlusion. This induces splanchnic vasodilation followed by intrarenal vasoconstriction ${ }^{16-18}$, that causes activation of the renin-angiotensin-aldosterone axis $^{12,19}$. This results in glomerular filtration rate reduction, disturbances in the excretion of sodium and water, acute tubular necrosis and renal failure ${ }^{12,16,20}$. Kidney injury worsens by the activation of pro-inflammatory cytokines (TNF-a, IL-6, IL-1), that drive renal parenchyma to appear significant inflammatory response.

Acute lung injury (ALI) induced by hepatic IRI also involves numerous risk factors ${ }^{21,22}$. One of the main mechanisms involved is excessive production of reactive oxygen species (ROS) after liver IRI ${ }^{23-25}$. Excessive production of ROS causes ALI by oxidative stress ${ }^{26,27}$, inflammatory responses and apoptosis ${ }^{28-30}$. ROS is related to the injury of the alveolar-capillary membrane and consequent transudation, that contributes to acute respiratory distress syndrome (ARDS) ${ }^{25}$. Significant morphological changes can be observed, such as perivascular edema and intravascular platelet aggregation revealing the deleterious effects of liver IRI on lungs ${ }^{23}$.

In this research protocol, the grade of hepatic IRI induced $A K I$ and $A L I$ is assessed by the expression of matrix metalloproteinases (MMPs), namely MMP2, MMP3, MMP9 and one of their inhibitors, TIMP2, that belong to a family of zinc dependent endopeptidases, capable of degrading extracellular matrix ${ }^{31}$. MMPs are associated with the breakdown of the glomerular basement membrane, renal scarring and fibrosis during the progression of kidney disease ${ }^{32-34}$. MMPs and their endogenous tissue inhibitors are involved in the pathogenesis of many lung disease $\mathrm{s}^{35,36}$ through extracellular matrix degradation and modulation of inflammation and fibrosis ${ }^{37}$.

Given that hepatic IRI induced AKI and ALI are common complications ${ }^{12}$, effective and preventive strategies are needed. Silibinin is a natural product that forms the major constituent of milk thistle seeds extract ${ }^{38}$ and it has promising hepatoprotective effects owing to its antioxidant and anti-inflammatory properties ${ }^{39-42}$. In-vitro studies have demonstrated anti-cancer effects against several types of cancer ${ }^{38}$. At the molecular level, silibinin decreases inflammatory responses through inhibition of $\mathrm{Nrf2}$ and Nf-kB signaling and suppressing the production of inflammatory cytokines, especially TNF- $\alpha^{40,41}$.

However, silibinin's extremely low water-solubility and the extensive first pass metabolism from liver limit its oral administration, while also prevent injectable administration $n^{43,44}$. Fortunately, the recently developed and in-vitro and in-vivo evaluated water-soluble lyophilized product of silibinin with hydroxypropyl- $\beta$-cyclodextrin (SLBHP- $\beta-C D$ ) was proven to be 10 times more bioavailable than pure silibinin ${ }^{43,44}$. Furthermore, our previous observations ${ }^{45-47}$ revealed that silibinin, when administered $i v$ in the form of SLB-HP- $\beta$-CD lyophilized product, diminishes the extent of injury, having protective effect on the liver and kidneys after hepatic IRI.

The purpose of the present experimental protocol was to evaluate the possible protective effect of silibinin, when administered intravenously in the form of its SLB-HP- $\beta-C D$ lyophilized product, on the observed acute lung injury and AKI after hepatic IRI. For this purpose, the expressions of MMP2, MMP3, MMP9 and TIMP2 on kidney and lung tissues were assessed.

\section{Methods}

\section{Animals and reagents}

Healthy male Wistar rats were utilized for the needs of the present study. All rats in the facility underwent regular screening according to a health-monitoring program, in compliance with the Federation of European Laboratory Animal Science Associations' recommendations. The study was approved by the Veterinary Authorities of Region of Athens, Greece (583/05-02-2015). The animal experiments were performed at the Department of Experimental Surgery, Bioresearch Foundation of the Academy of Athens. The immunohistochemistry study was performed at the Laboratory of Histology-Embryology, Faculty of Medicine, 
Democritus University of Thrace. The real-time quantitative reverse transcription polymerase chain reaction (qRT-PCR) study was performed at the School of Health Sciences, Department of Pharmacy, National and Kapodistrian University of Athens.

Preparation of SLB-HP- $\beta$-CD lyophilized product was implemented as previously described ${ }^{27,44}$. Briefly, $0.300 \mathrm{~g}$ of silibinin ( $M W=482.44$ ) and $1.860 \mathrm{~g}$ of HP- $\beta-C D$ ( $M W=1,540$ ) (both purchased from Sigma Aldrich, Steinheim, Germany, purity $>99 \%$ ) were transferred in a $300 \mathrm{~mL}$ volumetric flask and suspended with $200 \mathrm{~mL}$ of water (triple-deionized water from Millipore). Under continuous stirring and $\mathrm{pH}$ monitoring, small amounts of ammonium hydroxide were added until complete dissolution and $\mathrm{pH}$ adjustment between 9 and 10 . The solution at a molar ratio of 1:2 was freeze-dried by the usage of a Biobase Vacuum Freeze Dryer, BK-FD10T, Biobase Biodustry (Shandong) Co., to remove water and produce the water soluble lyophilized SLB-HP$\beta$-CD product. This powder was reconstituted in water for injection prior to administration, and the $\mathrm{pH}$ of the resulted solution was almost neutral.

\section{Experimental protocol}

Sixty-three Wistar male rats were assigned in one of three different groups, namely sham, control and silibinin groups. The median age of the animals was 13 weeks old, and their average weight was $314 \mathrm{~g}$. In the sham group ( $n=7$ rats), there was no intervention apart from opening and closing the abdomen. In the control group ( $C ; n=28$ rats), a $45-\mathrm{min}$ ischemia was applied followed by reperfusion. In the silibinin group ( $\mathrm{Si} ; \mathrm{n}=28$ rats), ischemia was applied again for $45 \mathrm{~min}$, and before reperfusion, SLB-HP- $\beta$-CD lyophilized product was administered intravenously.

The control and silibinin groups were then subdivided into time-point subgroups according to the duration of reperfusion and euthanasia time (i.e., C60, C120, C180, and C240 for $60,120,180$ and $240 \mathrm{~min}$, respectively, for the $C$ subgroups, and Si60, Si120, Si180 and Si240, respectively, for the Si subgroups).

The surgical procedure included placing the animals in a supine position and administration of isoflurane for general anesthesia. Also, proper analgesia based on subcutaneous administration of carpofen $(4 \mathrm{mg} / \mathrm{kg}$ ) was maintained for all groups.

Amid line laparotomy was performed under sterile conditions. For the sham group, there was only an openclose laparotomy. For the C group, a 45-min Pringle maneuver was performed by placing a micro-clip around the hepatoduodenal ligament, that was removed afterwards.
Prior to the removal of the micro-clip, $200 \mu \mathrm{L}$ of water for injection was administered intravenously. For the Si group, a 45-min Pringle maneuver was similarly performed, and prior to the removal of the micro-clip, $200 \mu$ L of SLB-HP- $\beta-C D$ lyophilized product, reconstituted in water for injection, was administered intravenously. The SLB concentration in the administered solution was $7.5 \mathrm{mg} / \mathrm{mL}$. Therefore, $200 \mu \mathrm{L}$ of this solution contained an administered dose of $1.5 \mathrm{mg}$ of silibinin, and its selection was based on literature data ${ }^{44,46}$.

\section{Sample collection}

Euthanasia was performed at the selected time points. Then, kidney and lung tissue samples were collected. Tissue samples from each group were snap-frozen in liquid nitrogen and stored at $-80^{\circ} \mathrm{C}$ until usage. Tissue specimens were fixed in formalin $10 \%$ and were paraffin embedded according to routine histological practice.

\section{qRT-PCR protocol}

\section{$\underline{\text { RNA isolation and cDNA synthesis }}$}

Total RNA was isolated using the NucleoZOL reagent, according to the manufacturer's instructions (Macherey-Nagel). Briefly, tissue specimens ( $100 \mathrm{mg}$ ) were homogenized with the addition of $1 \mathrm{~mL}$ of NucleoZOL reagent. Contaminants were precipitated by adding $400 \mu \mathrm{L}$ water/mL reagent, followed by rigorously mixing and incubation for $15 \mathrm{~min}$ at room temperature. After centrifugation for $15 \mathrm{~min}$ at $12,000 \mathrm{~g}$, the supernatants were transferred into new tubes. Total RNAs were precipitated after addition of $1 \mathrm{~mL}$ of isopropanol, incubation for $10 \mathrm{~min}$ at room temperature and centrifugation at $12,000 \mathrm{~g}$ for $10 \mathrm{~min}$ at $4^{\circ} \mathrm{C}$. The resulted RNA pellets were washed twice with $75 \%$ ethanol and centrifuged at $6,000 \mathrm{~g}$ for $3 \mathrm{~min}$ at $4^{\circ} \mathrm{C}$. After ethanol removal by decantation, RNAs were reconstituted in nuclease-free $\mathrm{H}_{2} \mathrm{O}$. RNA concentration and quality were accessed by spectrophotometry. All RNA samples were stored at $-80^{\circ} \mathrm{C}$.

First-strand cDNA was synthesized from $1 \mu \mathrm{g}$ total RNA, using the Transcriptor First Strand cDNA Synthesis Kit (Roche Diagnostics, Mannheim, Germany), according to the manufacturer's instructions. Each DNA-free RNA sample was added in a $20 \mu \mathrm{L}$ reaction containing the appropriate volumes of cDNA synthesis buffer, random primers, RNAse inhibitor (40 u) deoxynucleotide mix and transcriptor reverse transcriptase and incubated at $25^{\circ} \mathrm{C}$ for $10 \mathrm{~min}$, followed by incubation at $55^{\circ} \mathrm{C}$ for $30 \mathrm{~min}$, and finally at $85^{\circ} \mathrm{C}$ for $5 \mathrm{~min}$. All cDNA samples were stored at $-20^{\circ} \mathrm{C}$ until further analysis. 


\section{qRT-PCR methodology}

For qRT-PCR, gene-specific suitable pairs of primers and hybridization sets of dual probes (labelled with fluorescein donor and LC-Red 640 acceptor dyes) were used, as described in detail in Table 1. Each of the predicted qRT-PCR product spanned an intron-exon junction. Primers and probes were designed and synthesized by TIB Molbiol. Glyceraldehyde 3-phosphate dehydrogenase (GAPDH) was amplified as an internal control.

Table 1 - Sequences of primers and probes for RT-PCR methodologies.

\begin{tabular}{|c|c|}
\hline $\begin{array}{c}\text { Target } \\
\text { primer/ } \\
\text { probe }\end{array}$ & Oligonucleotide sequence $\left(5^{\prime} \rightarrow 3^{\prime}\right)$ \\
\hline MMP-9 F & GCTTTGCTGATGCTTCAGAA \\
\hline MMP-9 R & CAGAGTAGTTTTGGATCCAGTATGTG \\
\hline MMP-9 FL & CGAATGGCCTTTAGTGTCTGGCT- FL \\
\hline MMP-9 LC & LC640 TCCAGCTCACCAGTCTGGGGCA PH \\
\hline TIMP-2 F & CAGTATGAGATCAAGCAGATAAAGATGTT \\
\hline TIMP-2 R & GCTCTTCTCTGTGACCCAGTC \\
\hline TIMP-2 FL & GTACCAGATGGGCTGTGAGTGCAAGA FL \\
\hline TIMP-2 LC & LC CACTCGCTGTCCCATGATCCCTTG PH \\
\hline MMP-2 F & AGACAAAGAGTTGGCAGTGCAAT \\
\hline MMP-2 R & CTGTATGTGATCTGGTTCTTGTCCC \\
\hline MMP-2 FL & TCCGCATGGTCTCGATGGTGTTCTG FL \\
\hline MMP-2 LC & LC640 TCAAGGTCACCTGTCTGGGGCAGCC PH \\
\hline MMP-3 F & AGTGTGGATTCTGCCATTG \\
\hline MMP-3 R & GAGTTCCATAGAGGGACTGAATAC \\
\hline MMP-3 FL & CGTTCATCATCGTCAAAGTGAGCATC FL \\
\hline MMP-3 LC & LC640 CCATTAATCCCTGGTCCAGGTGCA PH \\
\hline GAPDH F & ATTCAACGGCACAGTCAAGG \\
\hline GAPDH R & GCATTAGCTTCAGATTTACGG \\
\hline GAPDH FL & CCAGAAGACTGTGGATGGCCCCT FL \\
\hline
\end{tabular}

RT-PCR: reverse transcription polymerase chain reaction; MMP: matrix metalloproteinase; GAPDH: glyceraldehyde 3-phosphate dehydrogenase.

The qRT-PCR was performed using the LightCycler ${ }^{\circledast}$ FastStart DNA Master HybProbe kit, according to the manufacturer's instructions (Roche Diagnostics, Mannheim,
Germany) on the Light Cycler 2.0 real-time instrument (Roche Diagnostics, Mannheim, Germany) in glass capillaries in the total volume of $20 \mu \mathrm{L}$. For the transcripts, $2 \mu \mathrm{L}$ of the sample cDNA was added to $1 \mu \mathrm{L}$ of the forward primer (with final concentration of $0.5 \mu \mathrm{M}$ ), $1 \mu \mathrm{L}$ of the reverse primer (with final concentration $0.5 \mu \mathrm{M}$ ), $1 \mu \mathrm{L}$ of the sensor probe (with final concentration $0.2 \mu \mathrm{M}$ ), $1 \mu \mathrm{L}$ of the anchor probe (with final concentration $0.2 \mu \mathrm{M}$ ), $1.8 \mu \mathrm{L} \mathrm{MgCl}$ (Roche Diagnostics, Mannheim, Germany, final concentration $2.25 \mathrm{mM}$ ), $2 \mu$ L Light Cycler Fast Start DNA Master HybProbe 10X (with final concentration 1X), and $\mathrm{ddH}_{2} \mathrm{O}$ to the final volume.

All reactions were performed according to the protocol described ahead. After pre-denaturation at $95^{\circ} \mathrm{C}$ for $10 \mathrm{~min}$, the following was carried out for 50 cycles: denaturation at $95^{\circ} \mathrm{C}$ for $5 \mathrm{~s}$, annealing at $60^{\circ} \mathrm{C}$ for $10 \mathrm{~s}$, extension at $72^{\circ} \mathrm{C}$ for $5 \mathrm{~s}$, and a cooling step at $40^{\circ} \mathrm{C}$ for $30 \mathrm{~s}$ in the last cycle. Relative expressions of MMP2, MMP3, MMP9 and TIMP2 transcript were performed by the usage of the comparative $\mathrm{Ct}$ method $^{48}$, a mathematical model that calculates changes in gene expression as a relative fold difference between an experimental and calibrator sample.

More specifically by using the $\Delta \Delta \mathrm{Ct}$ method, the Relative quantity can be calculated by Equation 1 :

$$
R=2^{-\Delta \Delta C t}
$$

In which:

$\Delta \Delta \mathrm{Ct}=\Delta \mathrm{Ct}$ (Si group) $-\Delta \mathrm{Ct}$ (control group);

$\Delta \mathrm{Ct}=\mathrm{Ct}$ (gene of interest) $-\mathrm{Ct}$ (GAPDH internal control).

$R$ values greater than 1 reflect a positive difference in the gene expression of Si group compared to the control animals, i.e., an increase in the expression of the gene of interest, while a value of $R<1$ reflects a negative difference in the gene expression of $\mathrm{Si}$ group in comparison with the control animals, i.e., a decrease in the expression of the gene of interest.

\section{Immunohistochemistry protocol}

Four- $\mu \mathrm{m}$ sections of representative blocks from each case were deparaffinized, rehydrated and treated with $0.3 \% \mathrm{H}_{2} \mathrm{O}_{2}$ for $5 \mathrm{~min}$ in methanol in order to prevent endogenous peroxidase activity. Afterwards, sections were immunostained by the peroxidase method (Super Sensitive One-Step Polymer-HRP Detection System, QD 630-XAKE, Biogenex). Slides were then incubated for $60 \mathrm{~min}$ with the antibodies MMP2 (mouse monoclonal, Novus Biological, NB 200-114) at 1:300 dilution, MMP3 (rabbit polyclonal, Nobus Biologicals, NB100-91878) at 1:70 dilution, MMP9 (rabbit polyclonal, Novus Biologicals, NBP1-57940) at 
1:250 dilution, and TIMP2 (mouse monoclonal, Novus Biologicals, NBP2-01573) at 1:300 dilution. Control slides were incubated for $60 \mathrm{~min}$ as well, with nonimmunized rabbit serum (negative control). A positive control was always run in the assay.

Bound antibody complexes, finally, were stained for 10 min with $0.05 \%$ diaminobenzidine. Afterwards, sections were briefly counterstained with Mayer's haematoxylin, mounted and examined under a Nikon Eclipse 50i microscope. The positive expression of antibodies was assessed by counting the number of stained cells (cytoplasmic or nuclear localization). The average labeling antibodies index was determined according to the proportion of positive cells, after scanning the entire section of the specimen. The levels of expression were evaluated as negative (0) for $<10 \%$ of stained cells, low (1) for $>10 \%$ and $<30 \%$ of stained cells, moderate ( 2 ) for $>30 \%$ and $<70 \%$ cells stained, and high ( 3 ) for $>70 \%$ cells stained.

\section{Statistical analysis}

Expression of MMP2, MMP3, MMP9 and TIMP2 (from $\mathrm{IHC}$ ) are presented with absolute and relative frequencies and median values with interquartile range (IQR). qRT-PCR results, expressed as relative to internal control (GAPDH) differences $(\Delta \mathrm{Ct})$, are presented with box and whiskers plots. Kolmogorov-Smirnov test revealed data were not normally distributed. Accordingly, the Kruskal-Wallis test was applied for the comparison of $\mathrm{Si}, \mathrm{C}$, and sham groups, while the Dunn's test, with the respective Bonferroni adjustment of $p$-values for multiple testing, was used for post-hoc pairwise comparisons. Two-tailed $p$-values are reported. Statistical significance was considered at 0.05 . Statistical analyses were performed using both the Statistical Package for the Social Sciences (SPSS) (version 26) and the R statistical package version 4.1.0.

\section{Results}

\section{Immunohistochemistry}

The difference in the expression of MMP2 in kidney between $\mathrm{C}$ and Si groups was not significant at 120 and $180 \mathrm{~min}$, but a significantly lower expression was found for the Si group at $240 \mathrm{~min}$ (Fig. 1a,b; Fig. 2a; Table 2). Silibinin group at 240 min had significantly lower expression of MMP3 in kidney, as compared to respective $\mathrm{C}$ group (Fig. 1c,d; Fig. 2b; Table 2). The difference in the expression of MMP9 in kidney between $\mathrm{C}$ and $\mathrm{Si}$ group did not reach statistical significance at 60, 120 and $180 \mathrm{~min}$, but a significantly lower expression was found for the Si group at $240 \mathrm{~min}$ (Fig. 1e,f;
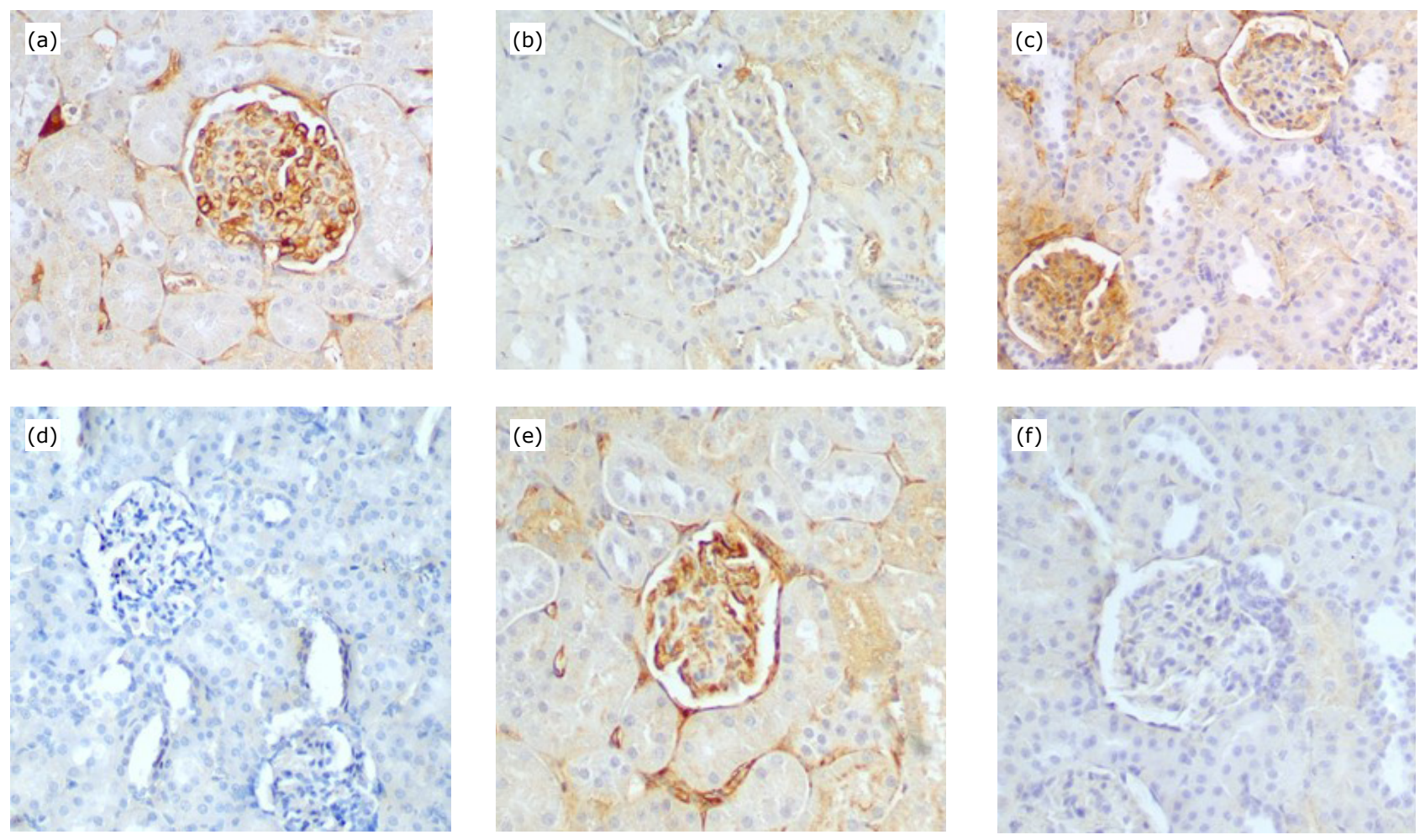

Figure 1 - Photomicrographs of $\operatorname{MMP2}(\mathbf{a}, \mathbf{b}), \operatorname{MMP3}(\mathbf{c}, \mathbf{d})$ and MMP9 $(e, f)$ in kidney of control $(\mathbf{a}, \mathbf{c}, \mathbf{e})$ and silibinin $(\mathbf{b}, \mathbf{d}, \mathbf{f})$ groups at $240 \mathrm{~min}$ (x200). 

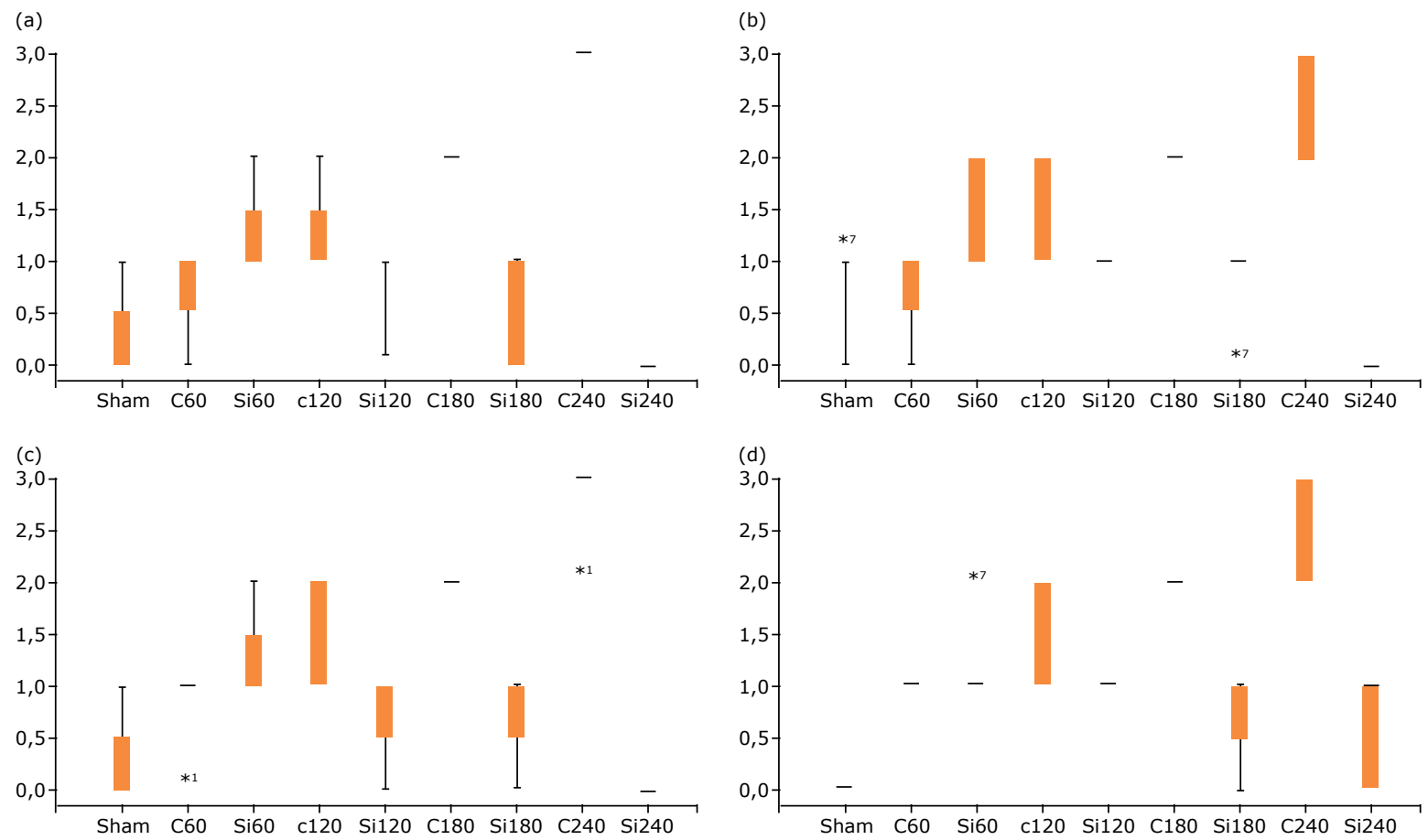

Figure 2 - Expression of kidney: (a) MMP2; (b) MMP3; (c) MMP9; (d) TIMP2. Middle boxes represent the inter-quartile range. Whiskers represent the lower and upper scores. Stars indicate the presence of outliers in the data set. A number indicates the serial number of the animal which has the outlying score. Kruskal-Wallis test (Dunn's test with Bonferroni adjustment).

Table 2 - Expression of MMP2 and MMP3 in kidney for all study groups and the results of the statistical analysis*.

\begin{tabular}{|c|c|c|c|c|c|c|c|c|c|c|}
\hline & \multicolumn{5}{|c|}{ MMP2 kidney } & \multicolumn{5}{|c|}{ MMP3 kidney } \\
\hline & 0 & 1 & 2 & 3 & Median & 0 & 1 & 2 & 3 & Median \\
\hline Group & N (\%) & N (\%) & N (\%) & N (\%) & (25th-75th) & N (\%) & N (\%) & N (\%) & N (\%) & (25th-75th) \\
\hline Sham & $5(71.4)$ & $2(28.6)$ & $0(0.0)$ & $0(0.0)$ & $0(0-1)$ & $6(85.7)$ & $1(14.3)$ & $0(0.0)$ & $0(0.0)$ & $0(0-0)$ \\
\hline $\mathrm{C} 60$ & $2(28.6)$ & $5(71.4)$ & $0(0.0)$ & $0(0.0)$ & $1(0-1)$ & $2(28.6)$ & $5(71.4)$ & $0(0.0)$ & $0(0.0)$ & $1(0-1)$ \\
\hline C120 & $0(0.0)$ & $5(71.4)$ & $2(28.6)$ & $0(0.0)$ & $1(1-2)$ & $0(0.0)$ & $4(57.1)$ & $3(42.9)$ & $0(0.0)$ & $1(1-2)$ \\
\hline $\mathrm{C} 180$ & $0(0.0)$ & $0(0.0)$ & $7(100.0)$ & $0(0.0)$ & $2(2-2)$ & $0(0.0)$ & $0(0.0)$ & $7(100.0)$ & $0(0.0)$ & $2(2-2)$ \\
\hline C240 & $0(0.0)$ & $0(0.0)$ & $0(0.0)$ & $7(100.0)$ & $3(3-3)$ & $0(0.0)$ & $0(0.0)$ & $3(42.9)$ & $4(57.1)$ & $3(2-3)$ \\
\hline Si60 & $0(0.0)$ & $5(71.4)$ & $2(28.6)$ & $0(0.0)$ & $1(1-2)$ & $0(0.0)$ & $4(57.1)$ & $3(42.9)$ & $0(0.0)$ & $1(1-2)$ \\
\hline Si120 & $0(0.0)$ & $7(100.0)$ & $0(0.0)$ & $0(0.0)$ & $1(1-1)$ & $0(0.0)$ & $7(100.0)$ & $0(0.0)$ & $0(0.0)$ & $0(0-0)$ \\
\hline Si180 & $3(42.9)$ & $4(57.1)$ & $0(0.0)$ & $0(0.0)$ & $1(0-1)$ & $1(14.3)$ & $6(85.7)$ & $0(0.0)$ & $0(0.0)$ & $1(1-1)$ \\
\hline Si240 & $7(100.0)$ & $0(0.0)$ & $0(0.0)$ & $0(0.0)$ & $0(0-0)$ & $7(100.0)$ & $0(0.0)$ & $0(0.0)$ & $0(0.0)$ & $0(0-0)$ \\
\hline \multicolumn{2}{|c|}{ P Sham vs. C60 } & & & & 1.000 & & & & & 1.000 \\
\hline \multicolumn{2}{|c|}{ P Sham vs. C120 } & & & & 0.682 & & & & & 0.179 \\
\hline \multicolumn{2}{|c|}{ P Sham vs. C180 } & & & & 0.004 & & & & & 0.003 \\
\hline \multicolumn{2}{|c|}{ P Sham vs. C240 } & & & & $<0.001$ & & & & & $<0.001$ \\
\hline \multicolumn{2}{|c|}{ P C60 vs. Si60 } & & & & 1.000 & & & & & 1.000 \\
\hline \multicolumn{2}{|c|}{ P C120 vs. Si120 } & & & & 1.000 & & & & & 0.061 \\
\hline \multicolumn{2}{|c|}{ P C180 vs. Si180 } & & & & 0.057 & & & & & 0.850 \\
\hline \multicolumn{2}{|c|}{ P C240 vs. Si240 } & & & & $<0.001$ & & & & & $<0.001$ \\
\hline
\end{tabular}

$\mathrm{N}$ : the number of animals and in parentheses the inter-quartile range; $25^{\text {th }}-75^{\text {th }}$ : the $25^{\text {th }}-75^{\text {th }}$ percentile; $\mathrm{P}: \mathrm{p}$-value from the Kruskal-Wallis test; $*$ the nonparametric Dunn's test was also applied for the comparison of $\mathrm{Si}, \mathrm{C}$ and sham groups with the respective Bonferroni adjustment of $\mathrm{p}$-values. 
Fig. 2c; Table 3). As shown in Table 3, the expression of TIMP2 in kidney was lower at 180 and $240 \mathrm{~min}$ (Fig. 2d).

The difference in the expression of MMP2 in lung between $\mathrm{C}$ and Si groups was not significant at 120 and
180 min, but a significantly lower expression was recorded for the Si group at $240 \mathrm{~min}$. When comparing C60-Si60 groups, MMP2 values in lung were statistically significantly higher for the Si group (Fig. 3 a,b; Fig. 4a; Table 4). Expression of

Table 3 - Expression of MMP9 and TIMP2 in kidney for all study groups and the results of the statistical analysis*.

\begin{tabular}{|c|c|c|c|c|c|c|c|c|c|c|}
\hline & \multicolumn{5}{|c|}{ MMP9 kidney } & \multicolumn{5}{|c|}{ TIM2 kidney } \\
\hline & 0 & 1 & 2 & 3 & Median & 0 & 1 & 2 & 3 & Median \\
\hline Group & N (\%) & N (\%) & N (\%) & N (\%) & (25th-75th) & N (\%) & N (\%) & N (\%) & N (\%) & (25th-75th) \\
\hline Sham & $5(71.4)$ & $2(28.6)$ & $0(0.0)$ & $0(0.0)$ & $0(0-1)$ & $7(100.0)$ & $0(0.0)$ & $0(0.0)$ & $0(0.0)$ & $0(0-0)$ \\
\hline $\mathrm{C} 60$ & $1(14.3)$ & $6(85.7)$ & $0(0.0)$ & $0(0.0)$ & $1(1-1)$ & $0(0.0)$ & $7(100.0)$ & $0(0.0)$ & $0(0.0)$ & $1(1-1)$ \\
\hline C120 & $0(0.0)$ & $4(57.1)$ & $3(42.9)$ & $0(0.0)$ & $1(1-2)$ & $0(0.0)$ & $3(42.9)$ & $4(57.1)$ & $0(0.0)$ & $2(1-2)$ \\
\hline C180 & $0(0.0)$ & $0(0.0)$ & $7(100.0)$ & $0(0.0)$ & $2(2-2)$ & $0(0.0)$ & $0(0.0)$ & $7(100.0)$ & $0(0.0)$ & $2(2-2)$ \\
\hline C240 & $0(0.0)$ & $0(0.0)$ & $1(14.3)$ & $6(85.7)$ & $3(3-3)$ & $0(0.0)$ & $0(0.0)$ & $4(57.1)$ & $3(42.9)$ & $2(2-3)$ \\
\hline Si60 & $0(0.0)$ & $5(71.4)$ & $2(28.6)$ & $0(0.0)$ & $1(1-2)$ & $0(0.0)$ & $6(85.7)$ & $1(14.3)$ & $0(0.0)$ & $1(1-1)$ \\
\hline Si120 & $2(28.6)$ & $5(71.4)$ & $0(0.0)$ & $0(0.0)$ & $1(0-1)$ & $0(0.0)$ & $7(100.0)$ & $0(0.0)$ & $0(0.0)$ & $1(1-1)$ \\
\hline Si180 & $2(28.6)$ & $5(71.4)$ & $0(0.0)$ & $0(0.0)$ & $1(0-1)$ & $2(28.6)$ & $5(71.4)$ & $0(0.0)$ & $0(0.0)$ & $1(0-1)$ \\
\hline $\mathrm{Si} 240$ & $7(100.0)$ & $0(0.0)$ & $0(0.0)$ & $0(0.0)$ & $0(0-0)$ & $4(57.1)$ & $3(42.9)$ & $0(0.0)$ & $0(0.0)$ & $0(0-1)$ \\
\hline \multicolumn{2}{|c|}{ P Sham vs. C60 } & & & & 1.000 & & & & & 0.548 \\
\hline \multicolumn{2}{|c|}{ P Sham vs. C120 } & & & & 0.179 & & & & & 0.003 \\
\hline \multicolumn{2}{|c|}{ P Sham vs. C180 } & & & & 0.003 & & & & & $<0.001$ \\
\hline \multicolumn{2}{|c|}{ P Sham vs. C240 } & & & & $<0.001$ & & & & & $<0.001$ \\
\hline \multicolumn{2}{|c|}{ P C60 vs. Si60 } & & & & 1.000 & & & & & 1.000 \\
\hline \multicolumn{2}{|c|}{ P C120 vs. Si120 } & & & & 0.061 & & & & & 1.000 \\
\hline \multicolumn{2}{|c|}{ P C180 vs. Si180 } & & & & 0.850 & & & & & 0.037 \\
\hline \multicolumn{2}{|c|}{ P C240 vs. Si240 } & & & & $<0.001$ & & & & & $<0.001$ \\
\hline
\end{tabular}

$\mathrm{N}$ : the number of animals and in parentheses the inter-quartile range; $25^{\text {th }}-75^{\text {th }}$ : the $25^{\text {th }}-75^{\text {th }}$ percentile; $\mathrm{P}$ : the $\mathrm{p}$-value from the Kruskal-Wallis test; *the nonparametric Dunn's test was also applied for the comparison of $\mathrm{Si}, \mathrm{C}$ and sham groups with the respective Bonferroni adjustment of $\mathrm{p}$-values.
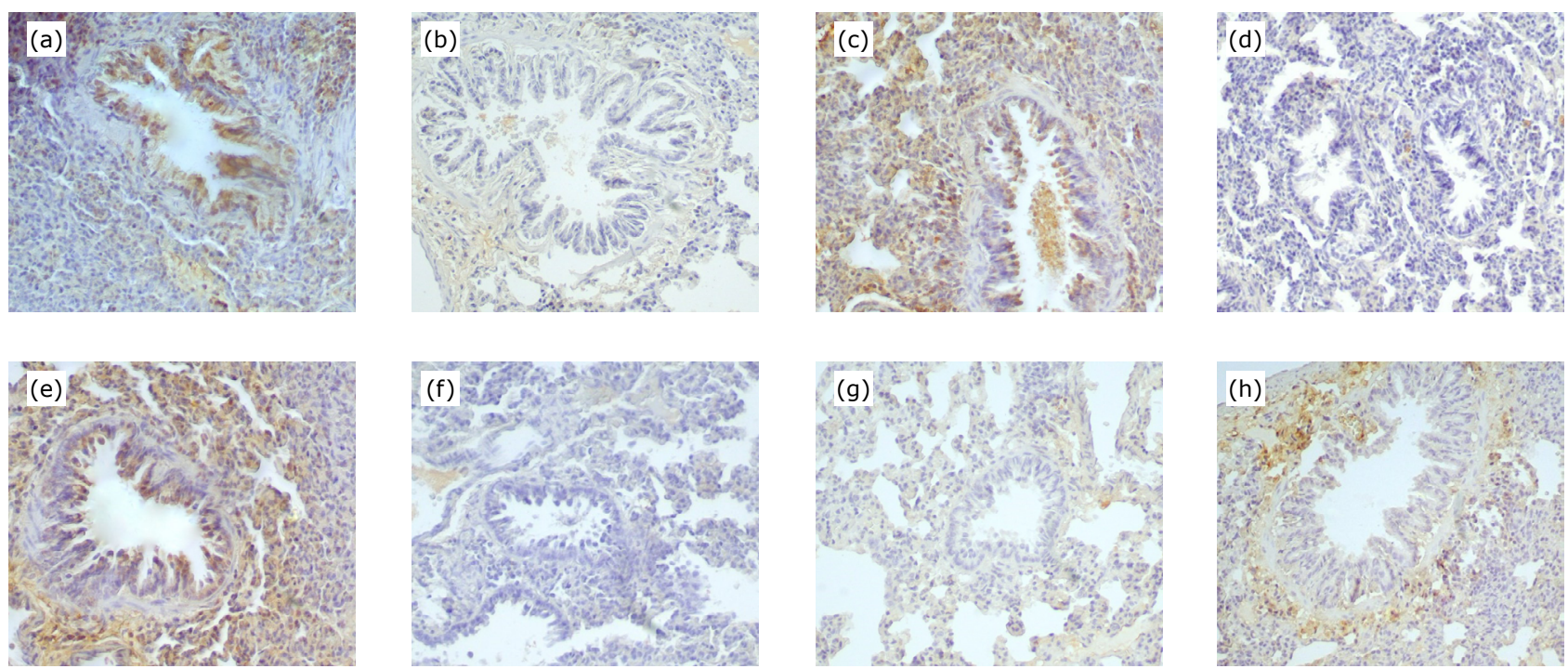

Figure 3 - Photomicrographs of MMP2 (a, b), MMP3 (c, d), MMP9 (e, f) and TIMP2 (g, h) in lung of control (a, c, e, g) and silibinin (b, d, f, h) groups at 240 min for MMP2, MMP3 and MMP9 and 180 min for TIMP2 (x200). 

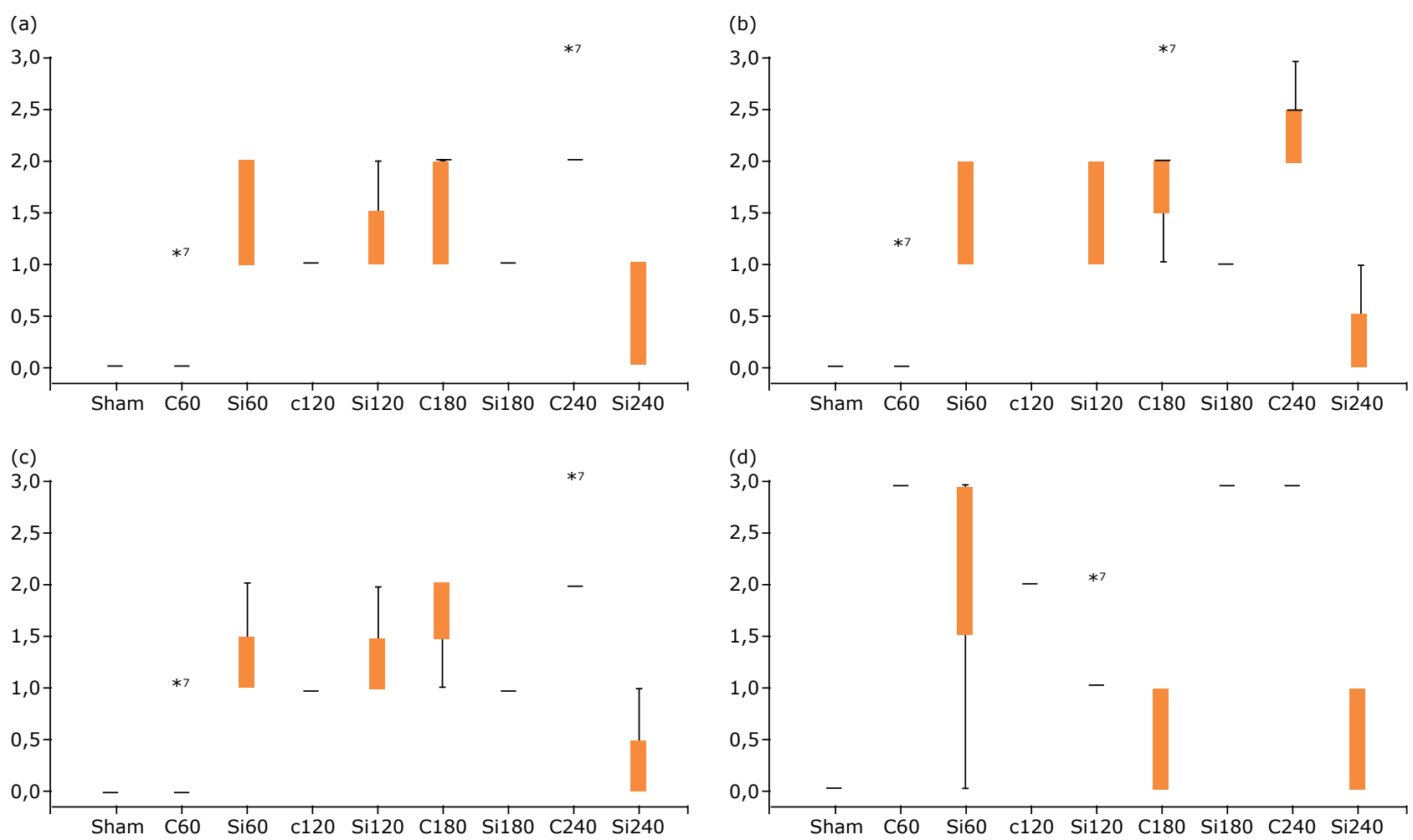

Figure 4-Expression of lung: (a) MMP2; (b) MMP3; (c) MMP9; (d) TIMP2. Middle boxes represent the inter-quartile range. Whiskers represent the lower and upper scores. Stars indicate the presence of outliers in the data set. A number indicates the serial number of the animal which has the outlying score. Kruskal-Wallis test (Dunn's test with Bonferroni adjustment).

Table 4 - Expression of MMP2 and MMP3 in lung for all study groups and the results of the statistical analysis*.

\begin{tabular}{|c|c|c|c|c|c|c|c|c|c|c|}
\hline & \multicolumn{5}{|c|}{ MMP2 lung } & \multicolumn{5}{|c|}{ MMP3 lung } \\
\hline & 0 & 1 & 2 & 3 & Median & $\mathbf{0}$ & 1 & 2 & 3 & Median \\
\hline Group & N (\%) & N (\%) & N (\%) & N (\%) & (25th-75th) & N (\%) & N (\%) & N (\%) & N (\%) & (25th-75th) \\
\hline Sham & $7(100.0)$ & $0(0.0)$ & $0(0.0)$ & $0(0.0)$ & $0(0-0)$ & $7(100.0)$ & $0(0.0)$ & $0(0.0)$ & $0(0.0)$ & $0(0-0)$ \\
\hline $\mathrm{C} 60$ & $6(85.7)$ & $1(14.3)$ & $0(0.0)$ & $0(0.0)$ & $0(0-0)$ & $6(85.7)$ & $1(14.3)$ & $0(0.0)$ & $0(0.0)$ & $0(0-0)$ \\
\hline C120 & $0(0.0)$ & $7(100.0)$ & $0(0.0)$ & $0(0.0)$ & $1(1-1)$ & $0(0.0)$ & $7(100.0)$ & $0(0.0)$ & $0(0.0)$ & $1(1-1)$ \\
\hline C180 & $0(0.0)$ & $3(42.9)$ & $4(57.1)$ & $0(0.0)$ & $2(1-2)$ & $0(0.0)$ & $2(28.6)$ & $4(57.1)$ & $1(14.3)$ & $2(1-2)$ \\
\hline C240 & $0(0.0)$ & $0(0.0)$ & $6(85.7)$ & $1(14.3)$ & $2(2-2)$ & $0(0.0)$ & $0(0.0)$ & $5(71.4)$ & $2(28.6)$ & $2(2-3)$ \\
\hline Si60 & $0(0.0)$ & $4(57.1)$ & $3(42.9)$ & $0(0.0)$ & $1(1-2)$ & $0(0.0)$ & $4(57.1)$ & $3(42.9)$ & $0(0.0)$ & $1(1-2)$ \\
\hline Si120 & $0(0.0)$ & $5(71.4)$ & $2(28.6)$ & $0(0.0)$ & $1(1-2)$ & $0(0.0)$ & $3(42.9)$ & $4(57.1)$ & $0(0.0)$ & $2(1-2)$ \\
\hline Si180 & $0(0.0)$ & $7(100.0)$ & $0(0.0)$ & $0(0.0)$ & $1(1-1)$ & $0(0.0)$ & $7(100.0)$ & $0(0.0)$ & $0(0.0)$ & $1(1-1)$ \\
\hline $\mathrm{Si} 240$ & $4(57.1)$ & $3(42.9)$ & $0(0.0)$ & $0(0.0)$ & $0(0-1)$ & $5(71.4)$ & $2(28.6)$ & $0(0.0)$ & $0(0.0)$ & $0(0-1)$ \\
\hline \multicolumn{2}{|c|}{ P Sham vs. C60 } & & & & 1.000 & & & & & 1.000 \\
\hline \multicolumn{2}{|c|}{ P Sham vs. C120 } & & & & 0.348 & & & & & 0.623 \\
\hline \multicolumn{2}{|c|}{ P Sham vs. C180 } & & & & 0.002 & & & & & 0.001 \\
\hline \multicolumn{2}{|c|}{ P Sham vs. C240 } & & & & $<0.001$ & & & & & $<0.001$ \\
\hline \multicolumn{2}{|c|}{ P C60 vs. Si60 } & & & & 0.037 & & & & & 0.093 \\
\hline \multicolumn{2}{|c|}{ P C120 vs. Si120 } & & & & 1.000 & & & & & 1.000 \\
\hline \multicolumn{2}{|c|}{ P C180 vs. Si180 } & & & & 1.000 & & & & & 1.000 \\
\hline \multicolumn{2}{|c|}{ P C240 vs. Si240 } & & & & 0.002 & & & & & 0.001 \\
\hline
\end{tabular}

$\mathrm{N}$ : the number of animals and in parentheses the inter-quartile range; $25^{\text {th }}-75^{\text {th }}$ : the $25^{\text {th }}-75^{\text {th }}$ percentile; $P$ : the $p$-value from the Kruskal-Wallis test; *the nonparametric Dunn's test was also applied for the comparison of $\mathrm{Si}, \mathrm{C}$ and sham groups with the respective Bonferroni adjustment of $\mathrm{p}$-values. 
MMP3 in lung is presented in Table 4. The expression of MMP3 in lung in the Si groups was significantly lower compared to the $\mathrm{C}$ group at 180 and $240 \mathrm{~min}$ (Fig. 3c,b; Fig. 4b; Table 4). The difference in the expression of MMP9 in lung between $\mathrm{C}$ and $\mathrm{Si}$ groups was not significant at 120 and $180 \mathrm{~min}$, but a significantly lower expression was found for the Si group at $240 \mathrm{~min}$ (Fig. 3e,f; Table 5). Silibinin groups at 60, 120 and 240 min did not have lower expression of TIMP2 in lung as compared to $\mathrm{C}$ groups at these time points. When comparing C180-Si180 groups, TIMP2 values were statistically significantly lower for the C group (Fig. 3g,h; Fig. 4d; Table 5).

\section{$\underline{q R T-P C R}$}

Results of qRT-PCR are shown in Figures 5 and 6. As far as kidney MMP2 is concerned, despite the trend for decreased gene expression in the Si group, due to the high variability, there is no statistically significant difference between $\mathrm{C}$ and $\mathrm{Si}$ groups at the same time points (Fig. 5a). Animals of Si group have a significantly lower expression of kidney MMP3 at 240 min and higher $\Delta \mathrm{Ct}$ value compared to the $\mathrm{C}$ group animals (Fig. $5 \mathrm{~b}$ ).
Furthermore, expression values of kidney MMP9 are significantly lower for the Si group at 180 and $240 \mathrm{~min}$ (and higher $\Delta \mathrm{Ct}$ values), when compared to the $\mathrm{C}$ at the same time points (Fig. 5c). TIMP2 expression values of renal parenchyma are significantly higher for the Si group at $120 \mathrm{~min}$ (and lower $\Delta \mathrm{Ct}$ value), while they decrease to a statistically significant level at $240 \mathrm{~min}$ (and higher $\Delta \mathrm{Ct}$ value), when compared to the values of the $C$ group (Fig. $5 \mathrm{~d}$ ).

Lung MMP2 and MMP3 expressions, as shown by the $q R T-P C R$ method, are statistically significantly lower for the Si group at $240 \mathrm{~min}$, when compared to the $C$ group (Fig. 6 a,b), while MMP9 has significantly lower values for the animals of the Si group at all time points compared to the animals of the $C$ group at the same time points (Fig. 6 b,c). As far as TIMP2 expression in lung parenchyma is concerned, there is no statistically significant difference between the two groups (Fig. 6d), probably due to the high variability observed.

These results are also reflected on the calculated Relative quantity $\left(R=2^{-\Delta \Delta c t}\right)$ values, presented in Table 6.

Table 5 - Expression of MMP9 and TIMP2 in lung for all study groups and the results of the statistical analysis*.

\begin{tabular}{|c|c|c|c|c|c|c|c|c|c|c|}
\hline & & & MMP9 It & & & & & TIM2 It & & \\
\hline & 0 & 1 & 2 & 3 & Median & 0 & 1 & 2 & 3 & Median \\
\hline Group & N (\%) & N (\%) & N (\%) & N (\%) & (25th-75th) & N (\%) & N (\%) & N (\%) & N (\%) & (25th-75th) \\
\hline Sham & $7(100.0)$ & $0(0.0)$ & $0(0.0)$ & $0(0.0)$ & $0(0-0)$ & $7(100.0)$ & $0(0.0)$ & $0(0.0)$ & $0(0.0)$ & $0(0-0)$ \\
\hline $\mathrm{C} 60$ & $6(85.7)$ & $1(14.3)$ & $0(0.0)$ & $0(0.0)$ & $0(0-0)$ & $0(0.0)$ & $0(0.0)$ & $0(0.0)$ & $7(100.0)$ & $3(3-3)$ \\
\hline C120 & $0(0.0)$ & $7(100.0)$ & $0(0.0)$ & $0(0.0)$ & $1(1-1)$ & $0(0.0)$ & $0(0.0)$ & $7(100.0)$ & $0(0.0)$ & $2(2-2)$ \\
\hline C180 & $0(0.0)$ & $2(28.6)$ & $5(71.4)$ & $0(0.0)$ & $2(1-2)$ & $4(57.1)$ & $3(42.9)$ & $0(0.0)$ & $0(0.0)$ & $0(0-1)$ \\
\hline $\mathrm{C} 240$ & $0(0.0)$ & $0(0.0)$ & $6(85.7)$ & $1(14.3)$ & $2(2-2)$ & $0(0.0)$ & $0(0.0)$ & $0(0.0)$ & $7(100.0)$ & $3(3-3)$ \\
\hline Si60 & $0(0.0)$ & $5(71.4)$ & $2(28.6)$ & $0(0.0)$ & $1(1-2)$ & $2(28.6)$ & $0(0.0)$ & $0(0.0)$ & $5(71.4)$ & $3(0-3)$ \\
\hline Si120 & $0(0.0)$ & $5(71.4)$ & $2(28.6)$ & $0(0.0)$ & $1(1-2)$ & $0(0.0)$ & $6(85.7)$ & $1(14.3)$ & $0(0.0)$ & $1(1-1)$ \\
\hline Si 180 & $0(0.0)$ & $7(100.0)$ & $0(0.0)$ & $0(0.0)$ & $1(1-1)$ & $0(0.0)$ & $0(0.0)$ & $0(0.0)$ & $7(100.0)$ & $3(3-3)$ \\
\hline $\mathrm{Si} 240$ & $5(71.4)$ & $2(28.6)$ & $0(0.0)$ & $0(0.0)$ & $0(0-1)$ & $4(57.1)$ & $3(42.9)$ & $0(0.0)$ & $0(0.0)$ & $0(0-3)$ \\
\hline P Shan & $\mathrm{n}$ vs. $\mathrm{C} 60$ & & & & 1.000 & & & & & $<0.001$ \\
\hline P Sham & vs. C120 & & & & 0.358 & & & & & 0.691 \\
\hline P Sham & vs. C180 & & & & 0.001 & & & & & 1.000 \\
\hline P Sham & vs. C240 & & & & $<0.001$ & & & & & $<0.001$ \\
\hline P C60 & vs. Si60 & & & & 0.135 & & & & & 1.000 \\
\hline P C120 & vs. Si120 & & & & 1.000 & & & & & 1.000 \\
\hline P C180 & vs. Si180 & & & & 1.000 & & & & & 0.006 \\
\hline P C240 & vs. Si240 & & & & $<0.001$ & & & & & 0.460 \\
\hline
\end{tabular}

$\mathrm{N}$ : the number of animals and in parentheses the inter-quartile range; $25^{\text {th }}-75^{\text {th }}$ : the $25^{\text {th }}-75^{\text {th }}$ percentile; $P$ : the $p$-value from the Kruskal-Wallis test; *the nonparametric Dunn's test was also applied for the comparison of Si, C and Sham groups with the respective Bonferroni adjustment of $p$-values. 

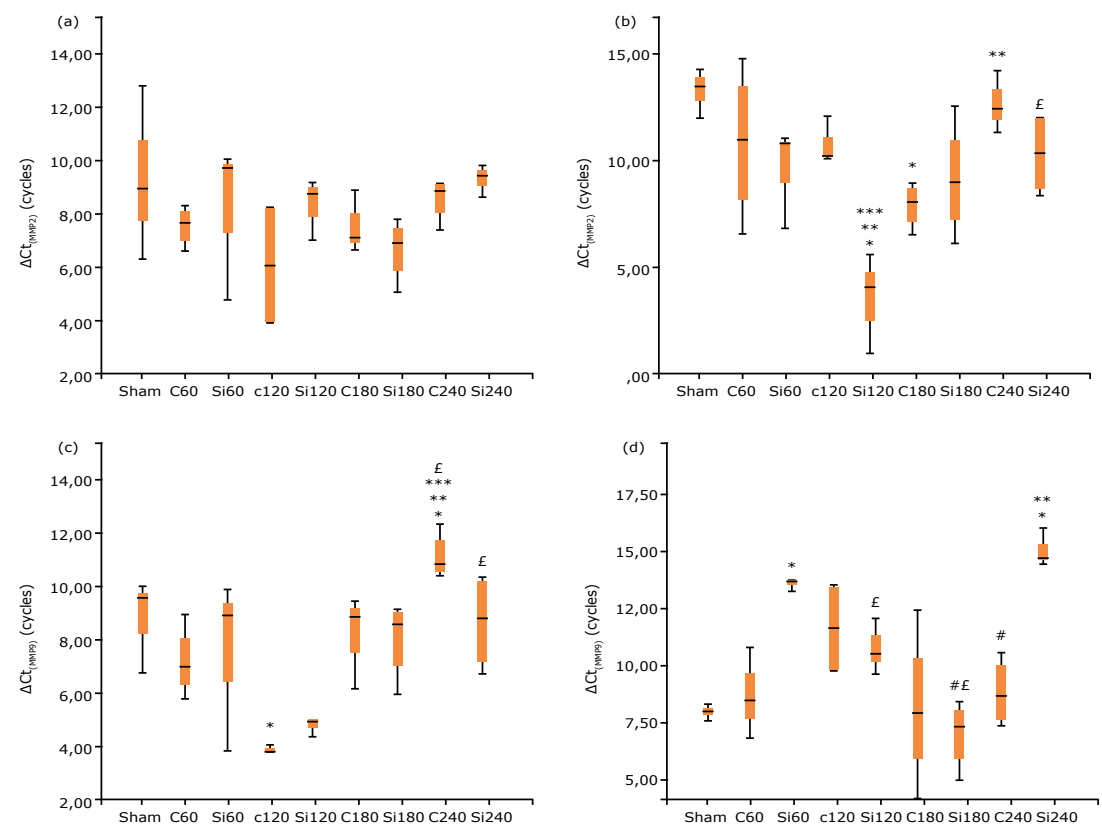

*In comparison to sham group, sham; **from time point $60 \mathrm{~min}$ of the same group; ***from time point 120 min of the same group; \# from time point 240 min of the same group; $f$ between control group, $\mathrm{C}$ and Silibinin group, Si, at the same time point; MMPs: matrix metalloproteinases; I/R: ischemia/reperfusion injury.

Figure 5 - Box and Whiskers plot for gene expression of MMPs in kidneys after liver IRI in Wistar rats: $\Delta \mathrm{Ct}_{\mathrm{MMP2}}$ (a), $\Delta \mathrm{Ct}_{\mathrm{MMP3}}(\mathbf{b})$, $\Delta \mathrm{Ct}_{\mathrm{MMP9}}$ (c) and $\Delta \mathrm{Ct}_{\mathrm{TIMP2}}$ (d). Kruskal-Wallis test (Dunn's test with Bonferroni adjustment). Statistically significant difference $\mathrm{p}<0.05$ :
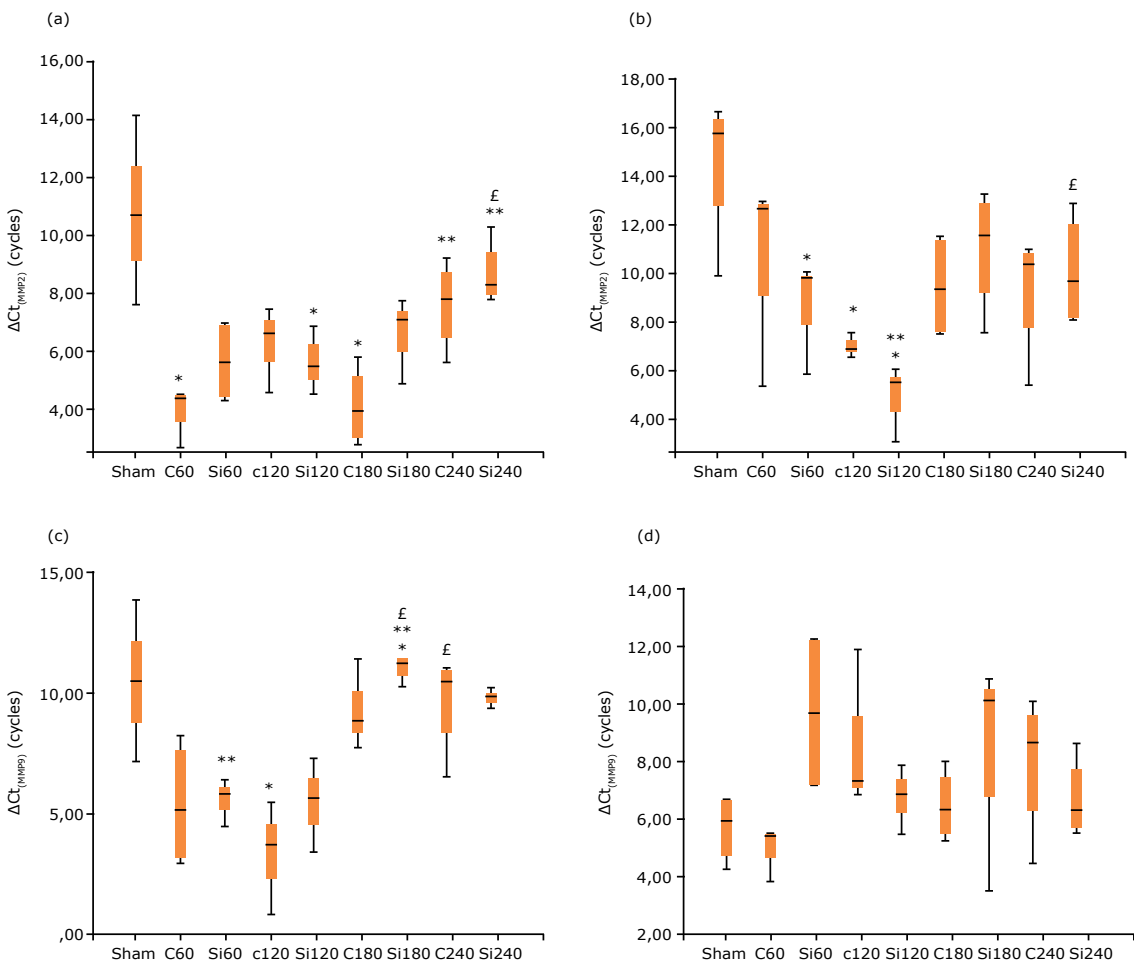

*In comparison to sham group, sham; ${ }^{* *}$ from time point 60 min of the same group; ${ }^{* *}$ from time point 120 min of the same group; \# from time point 240 min of the same group; $f$ between control group, $\mathrm{C}$ and Silibinin group, $\mathrm{Si}$, at the same time point; MMPs: matrix metalloproteinases; I/R: ischemia/reperfusion injury.

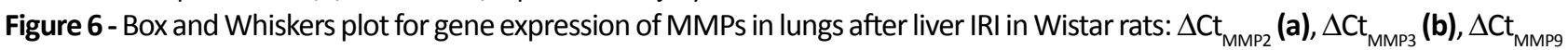
(c) and $\Delta \mathrm{Ct}_{\mathrm{TIMP2}}$ (d). Kruskal-Wallis test (Dunn's test with Bonferroni adjustment). Statistically significant difference $\mathrm{p}<0.05$. 
Table 6 - Relative quantity $\left(R=2^{-\Delta \Delta c t}\right)$ values for the effect of silibinin on MMP2, MMP3, MMP9 and TIMP2 gene expression in kidney and lung after hepatic IRI.

\begin{tabular}{|c|c|c|c|c|}
\hline \multirow{3}{*}{$\begin{array}{l}\text { Time after } \\
\text { I/R ( } \mathrm{min})\end{array}$} & \multicolumn{4}{|c|}{ Kidney } \\
\hline & \multicolumn{4}{|c|}{$R=2^{-\Delta \Delta C t}$} \\
\hline & MMP-2 & MMP-3 & MMP-9 & TIMP-2 \\
\hline 60 & 1.04 & 7.77 & 0.443 & 1.46 \\
\hline 120 & 2.87 & 1.33 & 0.701 & 102 \\
\hline 180 & 0.18 & 0.28 & 0.006 & 28.1 \\
\hline 240 & 0.52 & 0.009 & 0.065 & 0.049 \\
\hline \multirow{3}{*}{$\begin{array}{l}\text { Time after } \\
\text { I/R ( } \mathrm{min})\end{array}$} & \multicolumn{4}{|c|}{ Lung } \\
\hline & \multicolumn{4}{|c|}{$R=2^{-\Delta \Delta C t}$} \\
\hline & MMP-2 & MMP-3 & MMP-9 & TIMP-2 \\
\hline 60 & 0.87 & 2.81 & 0.075 & 0.345 \\
\hline 120 & 0.48 & 0.18 & 0.023 & 2.11 \\
\hline 180 & 0.38 & 0.211 & 0.013 & 1.01 \\
\hline 240 & 0.12 & 0.025 & 0.050 & 1.07 \\
\hline
\end{tabular}

I/R: ischemia/reperfusion injury.

\section{Discussion}

In the present study, distal renal and lung injury caused by hepatic IRI and the time-dependent protective action of silibinin were studied. AKI as well as ALI following hepatic IRI were confirmed by the elevated expression levels of MMP2, MMP3, MMP9 and TIMP2 in the control groups compared to sham.

The protective effect of silibinin on renal parenchyma was reflected on the observed reduced expression of MMP2 in the Si group compared to the C group. Also, its protective effect was confirmed by the reduced levels of expression of MMP3, MMP9 and TIMP2 in the Si group animals, as compared to the animals of the $C$ group, as shown by the results of immunohistochemistry method. The protective effect of silibinin on rat kidney was also supported by qRT-PCR results, showing reduction in the expression of kidney MMP3, for the animals of Si group, compared to the $C$ group animals. The silibinin renoprotective effect was also supported by the statistically significantly reduced expression level of kidney MMP9 and by the increased expression level of kidney TIMP2.

The protective effect of Silibinin on lung parenchyma was reflected on the observed reduced expressions of MMP2, MMP3 and MMP9 in the Si group compared to the C group. At 180 min after reperfusion, the level of expression of TIMP2 was notably elevated for the animals of the Si group. This makes a shift in the balance of MMP-TIMP2 in favor of TIMP2, reflecting the high protective effect of Si administration on lung parenchyma at that time point.

IHC findings reflecting Silibinin protective action on lung parenchyma are supported by qRT-PCR results, showing reduced expression levels of lung MMP2 and MMP3 at $240 \mathrm{~min}$. Its protective effect was also demonstrated by the statistically significantly decreased expression level of lung MMP9 at all time points after IRI for the animals of the Si group compared to those of the $C$ group.

Hepatic IRI causes significant ischemic injury in the hepatic parenchyma. Aside from that, it causes damage in remote organs such as kidneys and lungs through the production of pro-inflammatory mediators like TNF-a, IL-6, IL-1, and oxygen free radicals ${ }^{49-52}$. AKI and ALI following hepatic IRI are assessed by the level of expression of MMP2, MMP3, MMP9 and one of their inhibitors, TIMP2, a family of zinc-dependent endopeptidases that degrade extracellular matrix ${ }^{31}$ and are involved in many kidney and lung diseases ${ }^{32-37}$.

Previous studies have shown that hepatic IRI is strongly associated with $\mathrm{AKI}^{14,45,53}$. As shown in the study by Lee et $a l .{ }^{14}$, rats that underwent IRI for $60 \mathrm{~min}$ developed significant acute renal failure within 24 hours. Similarly, in Polat et al. ${ }^{15}$, renal functions were disturbed, and the level of oxidative stress was increased after $45 \mathrm{~min}$ of hepatic ischemia followed by 60 min of reperfusion in an experimental rat model. Kyriakopoulos et al. ${ }^{45}$ observed significant renal damage after $45 \mathrm{~min}$ of hepatic ischemia followed by $120 \mathrm{~min}$ of reperfusion in a rat model. In the present study, significant renal damage was recorded after $45 \mathrm{~min}$ of ischemia followed by 180 and $240 \mathrm{~min}$ of reperfusion.

Abu-Amara et al. ${ }^{54}$ tested the protective effect of nitric oxide, which maintains sufficient blood flow in the microcirculation of target organ, against the action of proinflammatory mediators released by IRI. Ramalho et al. ${ }^{55}$ studied the protective effect of rosmarinic acid on hepatocytes in a rat model of $60 \mathrm{~min}$ ischemia followed by 6 hours of reperfusion, concluding that rosmarinic acid reduced hepatocellular damage and all oxidative stress parameters. Sherif et al. ${ }^{56}$ found that vildagliptin ameliorated the remote renal injury that occurred after hepatic IRI by reducing the oxidative stress and the proinflammatory cytokine TNF-a. Meng et al. ${ }^{57}$ tested the renoprotective effect of polydatin against IRI by decreasing apoptosis and oxidative stress.

Sun et al. ${ }^{58}$ observed that octreotide reduced inflammation and apoptosis of renal tissue and preserved renal function by reducing the severity of injury in a rat model of $60 \mathrm{~min}$ hepatic ischemia followed by 24 hours of 
reperfusion. Abdel-Daim et al. ${ }^{59}$ tested the protective effect of rosuvastatin and vitamin $\mathrm{E}$ on liver and kidney against the damage caused by fipronil (FPN) in rats, concluding that they ameliorated the FPN induced hepatorenal toxicity through their anti-oxidative properties. In our study, the administration of silibinin after 45 min of hepatic ischemia showed its renoprotective effects at 180 and $240 \mathrm{~min}$ after reperfusion.

In previous studies, hepatic IRI inducing ALI has been well documented ${ }^{12,23,27,60-62}$. Ge et al. ${ }^{60}$ showed that hepatic IRI can induce remote ALI, accompanied by a significant increase of oxidative stress, in an experimental rat model of 60 min hepatic ischemia, reaching a pick at 6 hours after reperfusion, including alveolar damage and perivascular and peribronchial edema. In Colletti et al..$^{27}$, hepatic IRI induced ALI is confirmed by a number of alterations in lung pathophysiology in a rat model of $90 \mathrm{~min}$ hepatic ischemia. In Chan et al. ${ }^{23}$, it is shown that hepatic IRI induced a significant deterioration of lung functions including edema formation in a rat model of $90 \mathrm{~min}$ ischemia followed by 5 hours of reperfusion. In the present study, significant lung injury was recorded after $\mathbf{4 5}$ min of liver ischemia followed by 180 and 240 min of reperfusion.

In the study of Chan et al. ${ }^{23}$, the protective effect of propofol on lung tissue was tested. It attenuated remote pulmonary effects by decreasing ROS production after hepatic IRI. Yu et al..$^{63}$ tested the protective action of saquinavir on lung tissue, in an experimental rat model of $60 \mathrm{~min}$ ischemia followed by 6 and 12 hours of reperfusion, respectively. They demonstrated that administration of saquinavir attenuated lung injury by improving lung tissue and by reducing the expression of pro-inflammatory factors ${ }^{63}$. In our study, the protective effect of silibinin administration on lung parenchyma, after $45 \mathrm{~min}$ of hepatic ischemia, was shown at 180 and $240 \mathrm{~min}$ after reperfusion reaching a pick at $180 \mathrm{~min}$.

Silibinin, a non-toxic polyphenolic flavonoid, is the main active component extracted from a medicinal plant named Silybum marianum ${ }^{64}$. It was previously reported that silibinin has anti-inflammation, antifungal, antioxidant and antitumor activities ${ }^{38-44,46,47,65-67}$. Recently, experimental research protocols have been developed to study the possible protective activity of silibinin against $|R|^{46,53,65}$.

In the present study, comparison between sham and $C$ groups revealed that expression of MMP2, MMP3, MMP9 and TIMP2 in kidney was higher in the animals of the $C$ group at all time points, providing supporting evidence of renal damage due to the hepatic IRI that started being statistically significant after $180 \mathrm{~min}$ of reperfusion. Comparing the expression of MMP2, MMP3, MMP9 and TIMP2 in lung, between sham and $C$ groups, it was shown that the values of expression were significantly higher for the animals of the $C$ group at 180 and 240 min, revealing that lung damage due to hepatic IRI becomes statistically significant after 120 min of reperfusion.

Regarding the protective action of silibinin on kidney parenchyma, it was observed that the expression of the studied genes was decreased in the animals of the Si group in a time dependent manner. More specifically, expression of MMP2, MMP3, and MMP9 was significantly lower for the Si group at $240 \mathrm{~min}$. As far as the protective effect of silibinin on lung parenchyma is concerned, expression of MMP2, MMP3 and MMP9 was also significantly lower for the Si group at $240 \mathrm{~min}$. Silibinin offers high protective action on lung parenchyma at $180 \mathrm{~min}$ after reperfusion timepoint when the expression of TIMP2 was notably elevated.

From the mentioned observations, it becomes clear the time-dependent protective effect of silibinin both on kidney and lung parenchyma, when administered intravenously after $45 \mathrm{~min}$ of hepatic ischemia and before reperfusion. All studied renal and lung parameters were significantly improved at time points of $240 \mathrm{~min}$ after reperfusion.

Regarding the limitations of the present study, it should be pointed that the presented results are limited to the single dose administration protocol followed. However, these results consist of great evidence and challenge to extent the studies and explore the possible dose dependent protective effect of silibinin in kidney and lung after hepatic IRI. Furthermore, additional studies demonstrating the activation of MMPs would further clarify the role of these proteins in hepatic IRI.

\section{Conclusion}

Silibinin intravenous administration in the form of SLBHP- $\beta$-CD lyophilized product presented time-dependent protective effect on kidney and lung parenchyma following hepatic IRI based on both immunohistochemistry and qRT-PCR.

\section{Author's contribution}

Substantial contributions to design of the study: Tsaroucha A, Valsami G, Kostomistsopoulos N, Simopoulos $\mathrm{C}$ and Pikoulis E; Conception of the study: Tsaroucha A and Valsami G; Acquisition of data: Kollaras V; Statistical analysis: Lambropoulou M and Konstandi O; Manuscript preparation: Kollaras V, Tsaroucha A and Valsami G; Manuscript writing: Tsaroucha A and Simopoulos C, Critical revision: Tsaroucha A and Simopoulos C; Final approval of the version to be published: Tsaroucha $A$ and Simopoulos C.

\section{Data availability statement}

Data will be available upon request. 


\section{Funding}

Not applicable.

\section{Acknowledgments}

Not applicable.

\section{References}

1. Chouillard EK, Gumbs AA, Cherqui D. Vascular clamping in liver surgery: physiology, indications and techniques. Ann Surg Innov Res. 2010;4:2. https://doi.org/10.1186/17501164-4-2

2. Zhang B, Liu QH, Zhou CJ, Hu MZ, Qian HX. Protective effect of eNOS overexpression against ischemia/ reperfusion injury in small-for-size liver transplantation. Exp Ther Med. 2016;12(5):3181-8. https://doi. org/10.3892/etm.2016.3762

3. Zhai Y, Petrowsky H, Hong JC, Busuttil RW, KupiecWeglinski JW. Ischaemia-reperfusion injury in liver transplantation--from bench to bedside. Nat Rev Gastroenterol Hepatol. 2013;10(2):79-89. https://doi. org/10.1038/nrgastro.2012.225

4. Pringle JH. V. Notes on the arrest of hepatic hemorrhage due to trauma. Ann Surg. 1908;48(4):541-49. https://doi. org/10.1097/00000658-190810000-00005

5. Selzner M, Selzner N, Jochum W, Graf R, Clavien PA. Increased ischemic injury in old mouse liver: an ATPdependent mechanism. Liver Transpl. 2007;13(3):382-90. https://doi.org/10.1002/lt.21100

6. Cutrn JC, Perrelli MG, Cavalieri B, Peralta C, RosellCatafau J, Poli G. Microvascular dysfunction induced by reperfusion injury and protective effect of ischemic preconditioning. Free Radic Biol Med. 2002;33(9):1200-8. https://doi. org/10.1016/s0891-5849(02)01017-1

7. Selzner N, Rudiger H, Graf R, Clavien PA. Protective strategies against ischemic injury of the liver. Gastroenterology. 2003;125(3):917-36. https://doi. org/10.1016/s0016-5085(03)01048-5

8. Datta G, Fuller BJ, Davidson BR. Molecular mechanisms of liver ischemia reperfusion injury: insights from transgenic knockout models. World J Gastroenterol. 2013;19(11):1683-98. https://doi.org/10.3748/wjg.v19. i11.1683

9. Oliveira THC, Marques PE, Proost P, Teixeira MMM. Neutrophils: a cornerstone of liver ischemia and reperfusion injury. Lab Invest. 2018;98(1):51-62. https:// doi.org/10.1038/labinvest.2017.90

10. Guan L-Y, Fu P-Y, Li P-D, Li Z-N, Liu H-Y, Xin M-G, Li W. Mechanisms of hepatic ischemia-reperfusion injury and protective effects of nitric oxide. World J Gastrointest Surg. 2014;6(7):122-8. https://doi.org/10.4240/wjgs. v6.i7.122
11. Teoh NC, Farrell GC. Hepatic ischemia reperfusion injury: pathogenic mechanisms and basis for hepatoprotection. J Gastroenterol Hepatol. 2003;18(8):891-902. https://doi. org/10.1046/j.1440-1746.2003.03056.x

12. Nastos C, Kalimeris K, Papoutsidakis N, Tasoulis M-K, Lykoudis PM, Theodoraki K, Nastou D, Smyrniotis V, Arkadopoulos N. Global consequences of liver ischemia/ reperfusion injury. Oxid Med Cell Longev. 2014:906965. https://doi.org/10.1155/2014/906965

13. O'Riordan A, Wong V, McQuillan R, McCormick PA, Hegarty JE, Watson AJ. Acute renal disease, as defined by the RIFLE criteria, post-liver transplantation. Am J Transplant. 2007;7(1):168-76. https://doi.org/10.1111/j.1600-6143.2006.01602.x

14. Lee HT, Park SW, Kim M, D’Agati VD. Acute kidney injury after hepatic ischemia and reperfusion injury in mice. Lab Invest. 2009;89(2):196-208. https://doi.org/10.1038/labinvest

15. Polat C, Tokyol C, Kahraman A, Sabuncuoğlu B, Yilmaz $S$. The effects of desferrioxamine and quercetin on hepatic ischemia-reperfusion induced renal disturbance. Prostaglandins Leukot Essent Fatty Acids. 2006;74(6):37983. https://doi.org/10.1016/j.plefa

16. Davis CL, Gonwa TA, Wilkinson AH. Pathophysiology of renal disease associated with liver disorders: implications for liver transplantation. Part I. Liver Transpl. 2002;8(2):91109. https://doi.org/10.1053/jlts.2002.31516

17. Wadei HM, Mai ML, Ahsan N, Gonwa TA. Hepatorenal syndrome: pathophysiology and management. Clin J Am Soc Nephrol. 2006;1(5):1066-79. https://doi.org/10.2215/ CJN.01340406

18. Schepke M. Hepatorenal syndrome: current diagnostic and therapeutic concepts. Nephrol Dial Transplant. 2007;22 Suppl 8:viii2-4. https://doi.org/10.1093/ndt/gfm656

19. Fondevila C, Busuttil RW, Kupiec-Weglinski JW. Hepatic ischemia/reperfusion injury--a fresh look. Exp Mol Pathol. 2003;74(2):86-93. https://doi.org/10.1016/s00144800(03)00008-x

20. Davis CL, Gonwa TA, Wilkinson AH. Pathophysiology of renal disease associated with liver disorders: implications for liver transplantation. Part I. Liver Transpl. 2002;8(2):91109. https://doi.org/10.1053/jlts.2002.31516

21. Aduen JF, Stapelfeldt WH, Johnson MM, Jolles HI, Grinton SF, Divertie GD, Burger CD. Clinical relevance of time of onset, duration, and type of pulmonary edema after liver transplantation. Liver Transpl. 2003;9(7):764-71. https:// doi.org/10.1053/jlts.2003.50103

22. Jiang A, Liu C, Liu F, Song YL, Li QY, Yu L, Lv Y. Liver cold preservation induce lung surfactant changes and acute lung injury in rat liver transplantation. World J Gastroenterol. 2012;18(4):323-30. https://doi.org/10.3748/wjg.v18.i4.323

23. Chan KC, Lin CJ, LeePH, Chen CF, LaiYL,Sun WZ, Cheng YJ. Propofol attenuates the decrease of dynamic compliance and water content in the lung by decreasing oxidative radicals released from the reperfused liver. Anesth Analg. 2008;107(4):1284-9. https://doi.org/10.1213/ane.0b013e318181f4e6 
24. Goode HF, Webster NR, Howdle PD, Leek JP, Lodge JPA, Sadek SA, Walker BE. Reperfusion injury, antioxidants and hemodynamics during orthotopic liver transplantation. Hepatology. 1994;19(2):354-9.

25. Jaeschke H, Ramachandran A. Reactive oxygen species in the normal and acutely injured liver. J Hepatol. 2011;55(1):2278. https://doi.org/10.1016/j.jhep.2011.01.006

26. Nielsen VG, Tan S, Weinbroum A, McCammon AT, Samuelson PN, Gelman S, Parks DA. Lung injury after hepatoenteric ischemia-reperfusion: role of xanthine oxidase. Am J Respir Crit Care Med. 1996;154(5):1364-9. https://doi.org/10.1164/ajrccm.154.5.8912749

27. Colletti LM, Kunkel SL, Walz A, Burdick MD, Kunkel RG, Wilke CA, Strieter RM. Chemokine expression during hepatic ischemia/reperfusion-induced lung injury in the rat. The role of epithelial neutrophil activating protein. J Clin Invest. 1995;95(1):134-41. https://doi.org/10.1172/ $\mathrm{JCl} 117630$

28. Chen HW, Chien CT, Yu SL, Lee YT, Chen WJ. Cyclosporine A regulate oxidative stress-induced apoptosis in cardiomyocytes: mechanisms via ROS generation, iNOS and Hsp70. Br J Pharmacol. 2002;137(6):771-81. https:// doi.org/10.1038/sj.bjp.0704908

29. Wang X, Takahashi N, Uramoto H, Okada Y. Chloride channel inhibition prevents ROS-dependent apoptosis induced by ischemia-reperfusion in mouse cardiomyocytes. Cell Physiol Biochem. 2005;16(4-6):147-54. https://doi. org/10.1159/000089840

30. Wang C, Chen K, Xia Y, Dai WQ, Wang F, Shen M, Cheng P, Wang JS, Lu J, Zhang Y, Yang J, Zhu R, Zhang HW, Li JJ, Zheng YY, Zhou YQ, Guo CY. N-acetylcysteine attenuates ischemia-reperfusion-induced apoptosis and autophagy in mouse liver via regulation of the ROS/JNK/Bcl-2 pathway. PLoS One. 2014;9(9):e108855. https://doi.org/10.1371/ journal.pone.0108855

31. Sampieri CL, Orozco-Ortega RA. Matrix metalloproteinases and tissue inhibitors of metalloproteinases in chronic kidney disease and acute kidney injury: a systematic review of the literature. Hippokratia. 2018;22(3):99-104.

32. Dimas G, Iliadis F, Grekas D. Matrix metalloproteinases, atherosclerosis, proteinuria and kidney disease: Linkage-based approaches. Hippokratia. 2013;17(4):292-7.

33. Hernández-Hernández $\mathrm{ME}$, Morales-Romero J, Sampieri $\mathrm{CL}$, Lozano DJL, Lezama ICV, Contreras MJM, Hernández AR. Association of urinary activity of MMP-2 with microalbuminuria in an isolated sample of subjects living in high altitude rural locations in México. High Alt Med Biol. 2017;18(3):209-18. https://doi.org/10.1089/ ham.2016.0144

34. Parrish AR. Matrix metalloproteinases in kidney disease: role in pathogenesis and potential as a therapeutic target. Prog Mol Biol Transl Sci. 2017;148:31-65. https://doi. org/10.1016/bs.pmbts.2017.03.001
35. Hendrix AY, Kheradmand F. The role of matrix metalloproteinases in development, repair, and destruction of the lungs. Prog Mol Biol Transl Sci. 2017;148:1-29. https://doi.org/10.1016/bs.pmbts.2017.04.004

36. Greenlee KJ, Werb Z, Kheradmand F. Matrix metalloproteinases in lung: multiple, multifarious, and multifaceted. Physiol Rev. 2007;87(1):69-98. https://doi. org/10.1152/physrev.00022.2006

37. Zinter MS, Delucchi KL, Kong MY, Orwoll BE, Spicer AS, Lim MJ, Alkhouli MF, Ratiu AE, McKenzie AV, McQuillen PS, Dvorak CC, Calfee CS, Matthay MA, Sapru A. Early plasma matrix metalloproteinase profiles. a novel pathway in pediatric acute respiratory distress syndrome. Am J Respir Crit Care Med. 2019;199(2):181-9. https://doi. org/10.1164/rccm.201804-06780C

38. Davis-Searles PR, Nakanishi Y, Kim NC, Graf TN, Oberlies $\mathrm{NH}$, Wani MC, Wall ME, Agarwal R, Kroll DJ. Milk thistle and prostate cancer: differential effects of pure flavonolignans from Silybum marianum on antiproliferative end points in human prostate carcinoma cells. Cancer Res. 2005;65(10):4448-57. https://doi.org/10.1158/00085472.CAN-04-4662

39. Zhu XX, Ding YH, Wu Y, Qian LY, Zou H, He Q. Silibinin: a potential old drug for cancer therapy. Expert Rev Clin Pharmacol. 2016;9(10):1323-30. https://doi.org/10.1080/ 17512433.2016.1208563

40. Prabu SM, Muthumani M. Silibinin ameliorates arsenic induced nephrotoxicity by abrogation of oxidative stress, inflammation and apoptosis in rats. Mol Biol Rep. 2012;39(12):11201-16. https://doi.org/10.1007/s11033012-2029-6

41. Gupta SC, Tyagi AK, Deshmukh-Taskar P, Hinojosa M, Prasad $\mathrm{S}$, Aggarwal BB. Downregulation of tumor necrosis factor and other proinflammatory biomarkers by polyphenols. Arch Biochem Biophys. 2014;559:91-9. https://doi. org/10.1016/j.abb.2014.06.006

42. Alsaggar M, Bdour S, Ababneh Q, El-Elimat T, Qinna N, Alzoubi KH. Silibinin attenuates adipose tissue inflammation and reverses obesity and its complications in dietinduced obesity model in mice. BMC PharmacolToxicol. 2020;21(1):8. https://doi.org/10.1186/s40360-020-0385-8

43. Kellici TF, Ntountaniotis D, Leonis G, Chatziathanasiadou M, Chatzikonstantinou AV, Becker-Baldus J, Glaubitz C, Tzakos AG, Viras K, Chatzigeorgiou P, Tzimas S, Kefala E, Valsami G, Archontaki H, Papadopoulos MG, Mavromoustakos T. Investigation of the interactions of silibinin with 2-hydroxypropyl- $\beta$-cyclodextrin through biophysical techniques and computational methods. Mol Pharm. 2015;12(3):954-65. https://doi.org/10.1021/mp5008053

44. Christodoulou E, Kechagia IA, Tzimas S, Balafas E, Kostomitsopoulos N, Archontaki H, Dokoumetzidis A, Valsami G. Serum and tissue pharmacokinetics of silibinin after per os and i.v. administration to mice as a HP- $\beta-C D$ lyophilized product. Int J Pharm. 2015;493(1-2):366-73. https://doi.org/10.1016/j.ijpharm.2015.07.060 
45. Kyriakopoulos G, Tsaroucha AK, Valsami G, Lambropoulou M, Kostomitsopoulos N, Christodoulou E, Kakazanis Z, Anagnostopoulos C, Tsalikidis C, Simopoulos CE. Silibinin improves TNF- $\alpha$ and M30 expression and histological parameters in rat kidneys after hepatic ischemia/ reperfusion. J Invest Surg. 2018;31(3):201-9. https://doi.or $\mathrm{g} / 10.1080 / 08941939.2017 .1308044$

46. Tsaroucha AK, Valsami G, Kostomitsopoulos N, Lambropoulou M, Anagnostopoulos C, Christodoulou E, Falidas E, Betsou A, Pitiakoudis M, Simopoulos CE. Silibinin effect on Fas/FasL, HMGB1, and CD45 expressions in a rat model subjected to liver ischemia-reperfusion injury. J Invest Surg. 2018;31(6):491-502. https://doi.org/10.1080 /08941939.2017.1360416

47. Tsaroucha AK, Korovesis G, Valsami G, Lambropoulou M, Kollaras V, Anagnostopoulos C, Kostomitsopoulos $N$, Zerbini E, Simopoulos C. Silibinin-hydroxypropyl- $\beta$ cyclodextrin (SLB-HP- $\beta-C D$ ) complex prevents apoptosis in liver and kidney after hepatic ischemia-reperfusion injury. Food Chem Toxicol. 2020;145:111731. https://doi. org/10.1016/j.fct.2020.111731

48. Yibing Jia, Real-Time PCR. Methods in cell biology. Elsevier Inc; 2012. http://dx.doi.org/10.1016/B978-0-12-405914$6.00003-2$

49. Serteser M, Koken T, Kahraman A, Yilmaz K, Akbulut G, Dilek ON. Changes in hepatic TNF-alpha levels, antioxidant status, and oxidation products after renal ischemia/ reperfusion injury in mice. J Surg Res. 2002;107(2):234-40. https://doi.org/10.1006/jsre.2002.6513

50. Wanner GA, Ertel W, Müller P, Höfer $Y$, Leiderer R, Menger $M D$, Messmer K. Liver ischemia and reperfusion induces a systemic inflammatory response through Kupffer cell activation. Shock. 1996;5(1):34-40. https://doi. org/10.1097/00024382-199601000-00008

51. Tanaka Y, Maher JM, Chen C, Klaassen CD. Hepatic ischemia-reperfusion induces renal heme oxygenase-1 via NF-E2-related factor 2 in rats and mice. Mol Pharmacol. 2007;71(3):817-25. https://doi.org/10.1124/ mol.106.029033

52. Weinbroum AA, Hochhauser $E$, Rudick V, Kluger $Y$, Sorkine P, Karchevsky E, Graf E, Boher P, Flaishon R, Fjodorov D, Niv $D$, Vidne $B$. Direct induction of acute lung and myocardial dysfunction by liver ischemia and reperfusion. J Trauma. 1997;43(4):627-35. https://doi.org/10.1097/00005373199710000-00011

53. Tokyol C, Yilmaz S, Kahraman A, Cakar H, Polat C. The effects of desferrioxamine and quercetin on liver injury induced by hepatic ischaemia-reperfusion in rats. Acta Chir Belg. 2006;106(1):68-72. https://doi.org/10.1080/000154 58.2006.11679837

54. Abu-Amara M, Yang SY, Quaglia A, Rowley P, De Mel A, Tapuria N, Seifalian A, Davidson B, Fuller B. Nitric oxide is an essential mediator of the protective effects of remote ischaemic preconditioning in a mouse model of liver ischaemia/reperfusion injury. Clin Sci (Lond). 2011;121(6):257-66. https://doi.org/10.1042/CS20100598.
55. Ramalho LNZ, Pasta ÂA, Terra VA, Augusto M, Sanches SC, Souza-Neto FP, Cecchini R, Gulin F, Ramalho FS. Rosmarinic acid attenuates hepatic ischemia and reperfusion injury in rats. Food Chem Toxicol. 2014;74:270-8. https://doi. org/10.1016/j.fct.2014.10.004

56. Sherif IO, Alshaalan AA, Al-Shaalan NH. Renoprotective effect of vildagliptin following hepatic ischemia/ reperfusion injury. Ren Fail. 2020;42(1):208-15. https:// doi.org/10.1080/0886022X.2020.1729189

57. Meng QH, Liu HB, Wang JB. Polydatin ameliorates renal ischemia/reperfusion injury by decreasing apoptosis and oxidative stress through activating sonic hedgehog signaling pathway. Food Chem Toxicol. 2016;96:215-25. https://doi.org/ 10.1016/j.fct.2016.07.032.

58. Sun H, Zou S, Candiotti KA, Peng YH, Zhang QY, Xiao WQ, Wen YY, Wu J, Yang JF. Octreotide attenuates acute kidney injury after hepatic ischemia and reperfusion by enhancing autophagy. Sci Rep. 2017;7:42701. https://doi. org/10.1038/srep42701

59. Abdel-Daim MM, Abdeen A. Protective effects of rosuvastatin and vitamin $E$ against fipronil-mediated oxidative damage and apoptosis in rat liver and kidney. Food Chem Toxicol. 2018;114:69-77. https://doi. org/10.1016/j.fct.2018.01.055

60. Ge M, Chen C, Yao W, Zhou SL, Huang F, Cai J, Hei ZQ. Overexpression of Brg1 alleviates hepatic ischemia/ reperfusion-induced acute lung injury through antioxidative stress effects. Oxid Med Cell Longev. 2017;2017:8787392. https://doi.org/10.1155/2017/8787392

61. Peralta C, Perales JC, Bartrons R, Mitchell C, Gilgenkrantz $\mathrm{H}$, Xaus C, Prats N, Fernández L, Gelpí E, Panés J, RosellóCatafau J. The combination of ischemic preconditioning and liver $\mathrm{Bcl}-2$ overexpression is a suitable strategy to prevent liver and lung damage after hepatic ischemiareperfusion. Am J Pathol. 2002;160(6):2111-22. https:// doi.org/10.1016/S0002-9440(10)61160-1

62. Tüfek A, Tokgöz O, Aliosmanoglu I, Alabalik U, Evliyaoglu $O$, Çiftçi T, Güzel A, Yıldırım ZB. The protective effects of dexmedetomidine on the liver and remote organs against hepatic ischemia reperfusion injury in rats. Int J Surg. 2013;11(1):96-100. https://doi.org/10.1016/j. ijsu.2012.12.003

63. Yu Z, Tong Y, Zhang R, Ding X, Li Q. Saquinavir ameliorates liver warm ischemia reperfusion-induced lung injury via HMGB1- and P38/JNK-mediated TLR-4-dependent signaling pathways. Mediators Inflamm. 2017;2017:7083528. https://doi.org/10.1155/2017/7083528

64. Zou H, Zhu XX, Zhang GB, Ma Y, Wu Y, Huang DS. Silibinin: an old drugforhematologicaldisorders. Oncotarget.2017;8(51):893074. https://doi.org/10.18632/oncotarget.19153

65. Yun DG, Lee DG. Assessment of silibinin as a potential antifungal agent and investigation of its mechanism of action. IUBMB Life. 2017;69(8):631-7. https://doi. org/10.1002/iub.1647 
66. Davatgaran-Taghipour $\mathrm{Y}$, Masoomzadeh S, Farzaei $\mathrm{MH}$, Bahramsoltani R, Karimi-Soureh Z, Rahimi R, Abdollahi M. Polyphenol nanoformulations for cancer therapy: experimental evidence and clinical perspective. Int J Nanomedicine. 2017;12:2689-702. https://doi. org/10.2147/IJN.S131973
67. Wang $M$, Li YJ, Ding Y, Zhang H-N, Sun T, Zhang K, Yang L, Guo Y-Y, Liu S-B, Zhao M-G, Wu Y-M. Silibinin prevents autophagic cell death upon oxidative stress in cortical neurons and cerebral ischemia-reperfusion injury. Mol Neurobiol. 2016;53(2):932-43. https://doi.org/10.1007/ s12035-014-9062-5 